\title{
Adaptability Zoning for Salty-Tolerant Rice Varieties in Soc Trang Prefecture by Using GIS and Remote Sensing
}

\author{
Tran Thanh Dan ${ }^{1,2}$, Tran Thi Ngoc Trinh ${ }^{1}$, Vo Quang Minh ${ }^{1}$ and Huynh Ngoc Van ${ }^{3}$ \\ 1. Department of Land Resources, College of the Environment and Natural Resources, Can Tho University, Viet Nam \\ 2. Department of Science and Technology, Graduate School of Engineering, Nagasaki University, Japan \\ 3. Center of Seed and Plant Soc Trang province, Viet Nam
}

\begin{abstract}
Soc Trang is one of coastal provinces in which rice land is relatively low and therefore under annual threat of saline intrusion and other climatic variabilities. It raises an urgent need to identify various rice varieties which are short-duration, highly adaptive to salinity penetration, floods and aluminium poisonous matters, as well as high productivity and quality. The research applies the GIS (Geo-Information System) and RS (Remote Sensing) techniques to accurately evaluate the adaptability of different salinity-tolerant rice varieties. We have used information from FAO (The Food and Agriculture Organization), MapInfo and ArcGIS to map different components separately that are overlapped and mixed together to build different maps indicating the adaptability of different rice varieties to salinity in different locations in Soc Trang. We have also identified various factors affecting the productivity of these rice varieties. Then, several salinity-resistent rice varieties have been piloted in different areas to figure out which varieties are most suitable for specific regions.
\end{abstract}

Key words: Adaptability, salty-tolerant rice, climate change, remote sensing, GIS.

\section{Introduction}

GIS and remote sensing techniques can be applied to manage and process the spatial and non-spatial data for the construction of database systems, evaluation, and extrapolation in different fields. In particular, in the agricultural field, they can serve as a tool to classify adaptive land for new varieties, increase the efficiency of seed development, by selecting suitable areas, time can be saved in the growth of crops. Coastal provinces such as Soc Trang is affected by flooding and annual salinity penetration, these both affects agriculture even more than climate change, a problem shared by all crops. These problems have been largely affected the study area's rice production. Therefore, they affected people's lives. Hence, the main objective of this research was to evaluate the region where effected by salinity penetration and predicting the suitable zones for salinity-proof rice breeds based on the

Corresponding author: Tran Thanh Dan, Ph.D., research fields: Remote sensing and GIS applications, geoinfomatics, and natural disasters. characteristic of rice breeds, soils properties, and weather condition.

\section{Methodology}

\subsection{Study Area}

Soc Trang province is located in the Mekong delta in the South of Vietnam (Fig. 1). With a coastline of 72 $\mathrm{km}$ and an area of over $3,312 \mathrm{~km}^{2}$ [1], the province plays an important role in agricultural production and fisheries for the whole of Mekong delta, even Viet Nam. The coast of Soc Trang is protected from erosion by a narrow belt of mangrove forests. The coastal zone is facing a number of different threats. Climate change such as rising sea levels, environmental impacts like floods, salinity and unsustainable uses like deforestation in favor of rice cropping as well as shrimp farming, are just some of the challenges faced.

\subsection{Approach}

\subsubsection{Data Collection}

To evaluate land adaptation for salinity-proof rice 
breeds in the present natural conditions, experiment of these different salinity-proof rice breeds on different areas in Soc Trang province, this research uses theory of land evaluation of FAO [3, 4], physiology, ecology of rice breeds, land use planning.

Landsat imagery in February to June in 2011 was used in this research. The data downloaded from the USGS website (http://earthexplorer.usgs.gov/), and processed in the level L1 (geometrically corrected with UTM, WGS zone 48N datum system).

\subsubsection{Methodology}

Procedure for methodology presents step by step:

Step 1: Building adaptive classification table

Build an adaptive land classification table for rice cultivation under natural conditions based on the following evaluated features: selection of land quality, characteristics of rice production and socio-economic conditions.

\section{Step 2: Construction spatial data}

The collected data were digitized and analyzed through an overlaying process to generate a spatial map such as rainfall distribution, depth of flooding, soil and salinity.

Landsat imagery was interpreted to determine the current state of cultivation zone. They were also used to adjust and map the province's salinity.

Step 3: Evaluate the adaptability of salinity-proof rice breeds

Rice varieties were selected to evaluate their adaptability on the land designated for rice cultivation. Based on the diagnosis of land quality and the diagnosis of factors for rice breeds selection, the necessary elements were compared with the requirements of land for rice breeds use to access decentralization for four different categories: high adaptation (S1), average adaptation (S2), poor adaptation (S3), non-adaptation (N).

Step 4: Zoning adaptation of salinity-proof rice breeds.

Step 5: The good quality and insect resistance of new rice varieties are used for field experiment at saline soil under shrimp cultivation area in the three region (selected by Center of Seed and Plant Soc Trang Province), as follows:

- Tan Qui A hamlet, Tan Hung commune, Long Phu district;

- Nguyen Tang hamlet, Dai An $1^{\text {st }}$ commune, $\mathrm{Cu}$ Lao Dung commune;

- Luong Van Hoang hamlet, Ngoc To commune, My Xuyen commune.

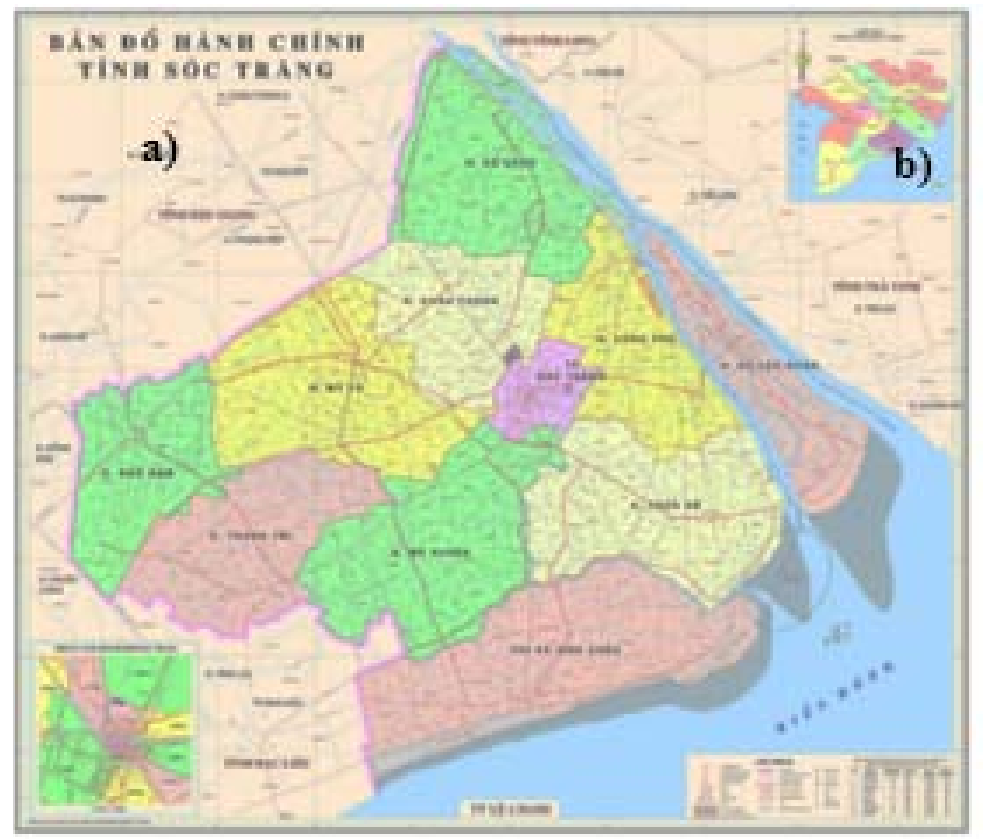

Fig. 1 Study area-Soc Trang province (a) and the Mekong delta (b). 
(1) Seed varieties: new rice prospective with salt tolerant rice varieties were chosen though prior experiments;

(2) Experiment design: field experiments were carried out with a randomized complete block design with three times replication;

(3) Soil preparation was puddled and leveled with a mid-size tractor, to around 10 to $20 \mathrm{~cm}$ depth before transplanting. Selective herbicide was sprayed before transplanting to control weeds. Besides, the yellow snails were killed by snail poisonous substance;

(4) Seeding, transplanting: for each variety, the method of seeding consisted in broadcasting germinated seeds over the soil surface bed $(1 \times 2 \mathrm{~m})$. The soil was irrigated 2-3 times per day by a spray irrigation system. After sowing 14-16 days, rice was transplanted into the experiment field with a density of $15 \times 15 \mathrm{~cm}$. The soil was continuously irrigated at 2 to $3 \mathrm{~cm}$ depth during the rice-cropping season;

(5) Fertilizer application: fertilizer was applied by broadcasting at a rate: $90 \mathrm{~N}-60 \mathrm{P} 2 \mathrm{O} 5-30 \mathrm{~K} 2 \mathrm{O}$ (kgha-1) in four splits: basal applied before transplanting the rice, then 5, 15 and 30-35 days after transplant. This fertilizer dose can be adjusted depending on the rice growth conditions of field experiments;

(6) Field measurements:

- Salinity of field water: at transplant time 15,40 , 60 days after transplant, and at harvest time of the rice crop;

- Rice salt tolerance: evaluation of rice growth under saline condition according to the IRRI classification (Tab. 1) at 15, 40 and 70 days after transplant;

- Duration of rice growth at harvesting stage (when at least $85 \%$ of the upper portion of rice panicles turns straw colored);

- The height of rice at harvesting stage;

- A rice plot of $5 \mathrm{~m}^{2}$ was harvested for each treatment and yield was standardized to kg.ha-1 of total grain (14\% moisture);

- Rice yield components of 12 plants (tiller, thousand-grain weight, filled grain percentage, grain per panicle and panicle number per $\mathrm{m}^{2}$ ) were collected.

Analysis of the results carried out with Excel and IRRISTAS software.

\section{Results and Discussion}

\subsection{Result of Mapping Water Salinity}

According to the measurement results in Table 2, the salinity level is high at estuary and decreases gradually in interior field. Annual salinity penetration started in January. It is the highest in April as well as at high tide. The salinity level decreases slowly when the first rain sap pear and fresh water from upstream flows down.

In dry season, high terrain and coastal areas deprived of fresh water for rice due to the upstream flowing down, even with channel systems. At the end of the dry season, coastal areas often do not have enough fresh water to irrigate the northwest region whereas from September to October, the contiguous HauGiang province is flooded frequently [2]. The North and North-West regions of the Soc Trang province are not affected by salinity so the areas are suitable for three rice crops per year. Rice crop in Summer-Autumn usually starts early from March to April due to sufficient fresh water to irrigate and harvest time in June (rice breeds within 100 days growth duration).

Table 1 Standard evaluation score of visual salt injury of rice (IRRI classification).

\begin{tabular}{lll}
\hline Score & Observation & Tolerance \\
\hline 1 & Normal grow, no leaf symptoms & Highly tolerant \\
3 & Nearly normal growth, but leaf tips or few leaves whitish and rolled & Tolerant \\
5 & Severely retarded growth; most leaves rolled; only a few are elongating & Moderately tolerant \\
7 & Complete cessation of growth; most leaves dry; some plants dying & Susceptible \\
9 & Almost all plants dead or dying & Highly susceptible \\
\hline
\end{tabular}


Table 2 Average concentration of salinity (\%) in the 3 years (09-10-11).

\begin{tabular}{|c|c|c|c|c|c|c|c|c|c|c|c|c|c|c|c|c|c|c|}
\hline \multirow{2}{*}{$\begin{array}{l}\text { Salinity } \\
\text { measuring } \\
\text { station }\end{array}$} & \multicolumn{3}{|c|}{ January } & \multicolumn{3}{|c|}{ February } & \multicolumn{3}{|c|}{ March } & \multicolumn{3}{|c|}{ April } & \multicolumn{3}{|c|}{ May } & \multicolumn{3}{|c|}{ June } \\
\hline & 2009 & 2010 & 2011 & 2009 & 2010 & 2011 & 2009 & 2010 & 2011 & 2009 & 2010 & 2011 & 2009 & 2010 & 2011 & 2009 & 2010 & 2011 \\
\hline An Lac Tay & 0 & 0.0 & 0.0 & 0.1 & 0.1 & 0.0 & 0.1 & 0.8 & 3.5 & 0.4 & 1.4 & 3.9 & 0.1 & 0.4 & 0.0 & 0 & 0.0 & 0.0 \\
\hline Dai Ngai & 0.2 & 0.0 & 5.0 & 0.6 & 1.7 & 6.3 & 1.4 & 6.0 & 11.1 & 5.3 & 7.4 & 10.4 & 1.2 & 4.3 & 4.2 & 0.3 & 0.0 & 0.0 \\
\hline Long Phu & 1.9 & 0.0 & 7.8 & 3 & 6.2 & 10.2 & 5.3 & 12.8 & 17.8 & 10 & 16.3 & 14.8 & 3.4 & 13.4 & 9.3 & 1.5 & 0.0 & 0.0 \\
\hline Soctrang city & 0.1 & 0.0 & 3.0 & 0.3 & 1.2 & 2.3 & 0.5 & 2.4 & 4.0 & 1.5 & 4.1 & 3.3 & 0.7 & 2.5 & 1.6 & 0.4 & 0.0 & 0.0 \\
\hline Thanh Phu & 0.3 & 0.0 & 2.3 & 0.8 & 3.9 & 5.1 & 2.5 & 7.9 & 9.5 & 6.3 & 12.6 & 9.4 & 3.3 & 13.6 & 10.5 & 1.3 & 0.0 & 0.0 \\
\hline Tran De & 7.2 & 0.0 & 18.6 & 9.8 & 14.5 & 18.1 & 11.7 & 19.3 & 23.1 & 17.9 & 20.4 & 20.3 & 11 & 18.0 & 17.7 & 7.2 & 0.0 & 0.0 \\
\hline
\end{tabular}

(Source: Department of Irrigation Soc Trang province, 2011 [2]).
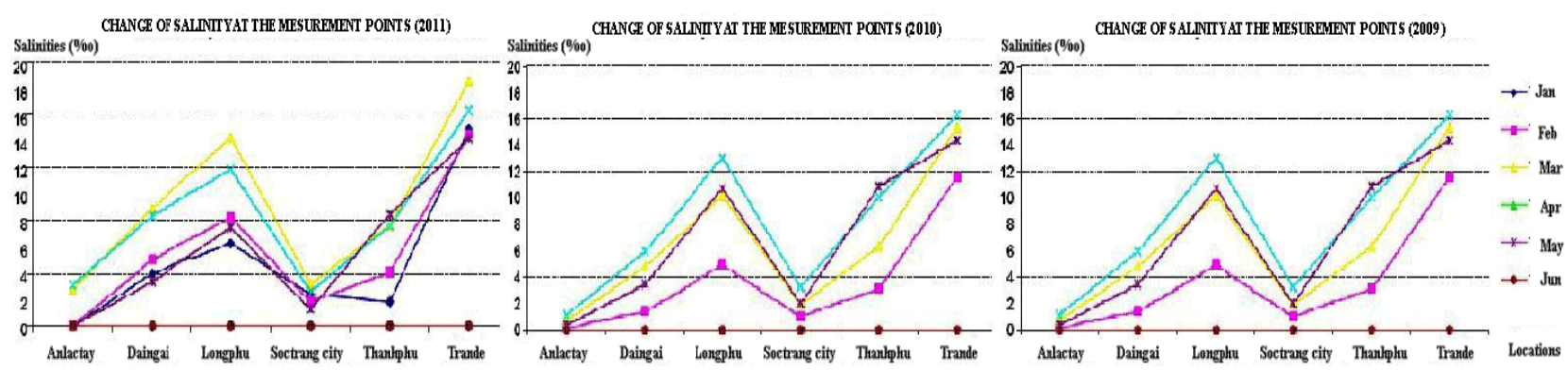

Fig. 2 Chart of salinity concentration unfolding at the measuring stations.

Table 2 shows the average concentration of salinity from 2009 to 2011 . The salinity penetration in 2010 occurred later than in 2009 and 2011. Normally, it appeared in January with increasing concentration of salinity. The Tran De station where salinity intrusion are highest compared with the other stations, showed up to $18.6 \%$ salinity in January 2011 while in January 2009, it was only 7.2\%. Apart from the Tran De station, Long Phu station is another station where salinity intrusion occurs earlier and higher than other stations (An Lac Tay, Dai Ngai, Thanh Phu and Soc Trang). Highest concentration of salinity appears March and April in all stations, to avoid this rice cropping decreases.

Salinity maps (Fig. 4) were created through accurate information about the present state of GS+ and Landsat images (Fig. 3). The advantages of vegetation, furthermore, they were used to adjust the Landsat images are that they reflect complete and salinity boundaries.

Based on the characteristics, singularities, spectral and distribution of land cover in Landsat imagery in 2011, there is a close relationship between the present of land use and the determination of salinity boundary inside. In addition, the experiences as well as expert opinions in the area, they were possible to detect salinity that had penetrated further into the inland, particularly in the stations of Tran De, My Xuyen and Nga Nam.

\subsection{Results of Mapping Land Units under Natural Conditions}

A land unit map (Fig. 5) is made as a basis background for determining the scope of the adaptive salinity-roof rice breeds. It was used to find homogeneous land units of natural elements. The land unit map was created through the combination of single maps such as rainfall map, soil map, salinity map and elevation map. A threshold selection for the land unit represents in Table 3. For the soil map, it has 19 soil types.

\subsection{Adapted Decentralization for Advance Salinity-proof Rice Breeds}

3.3.1 Decentralization Factor for the Land Unit

Based on the land units, characteristics of the breed 

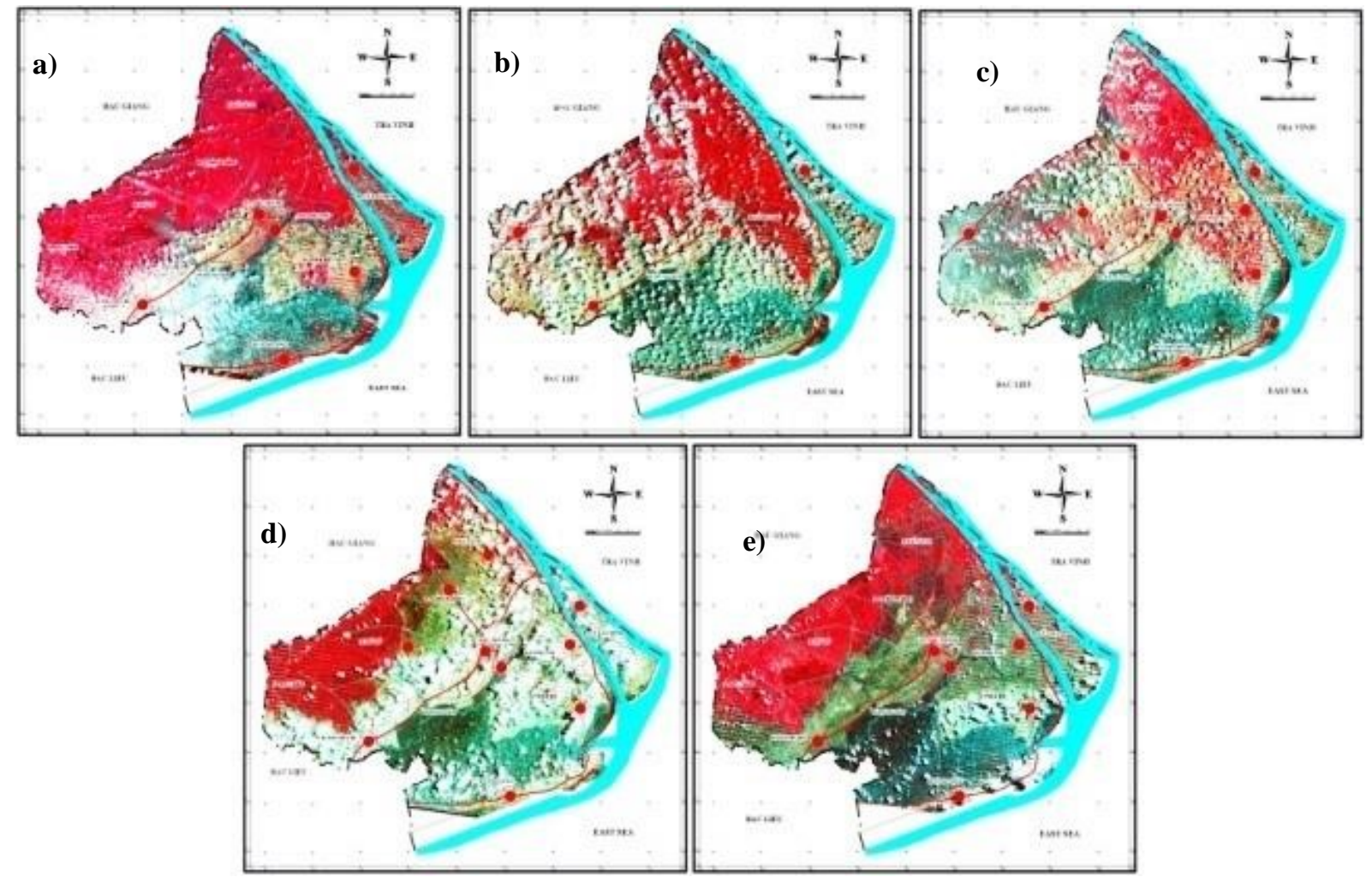

Fig. 3 Landsat images in Soc Trang province in 2011. a) February, b) March, c) April, d) May and e) June.
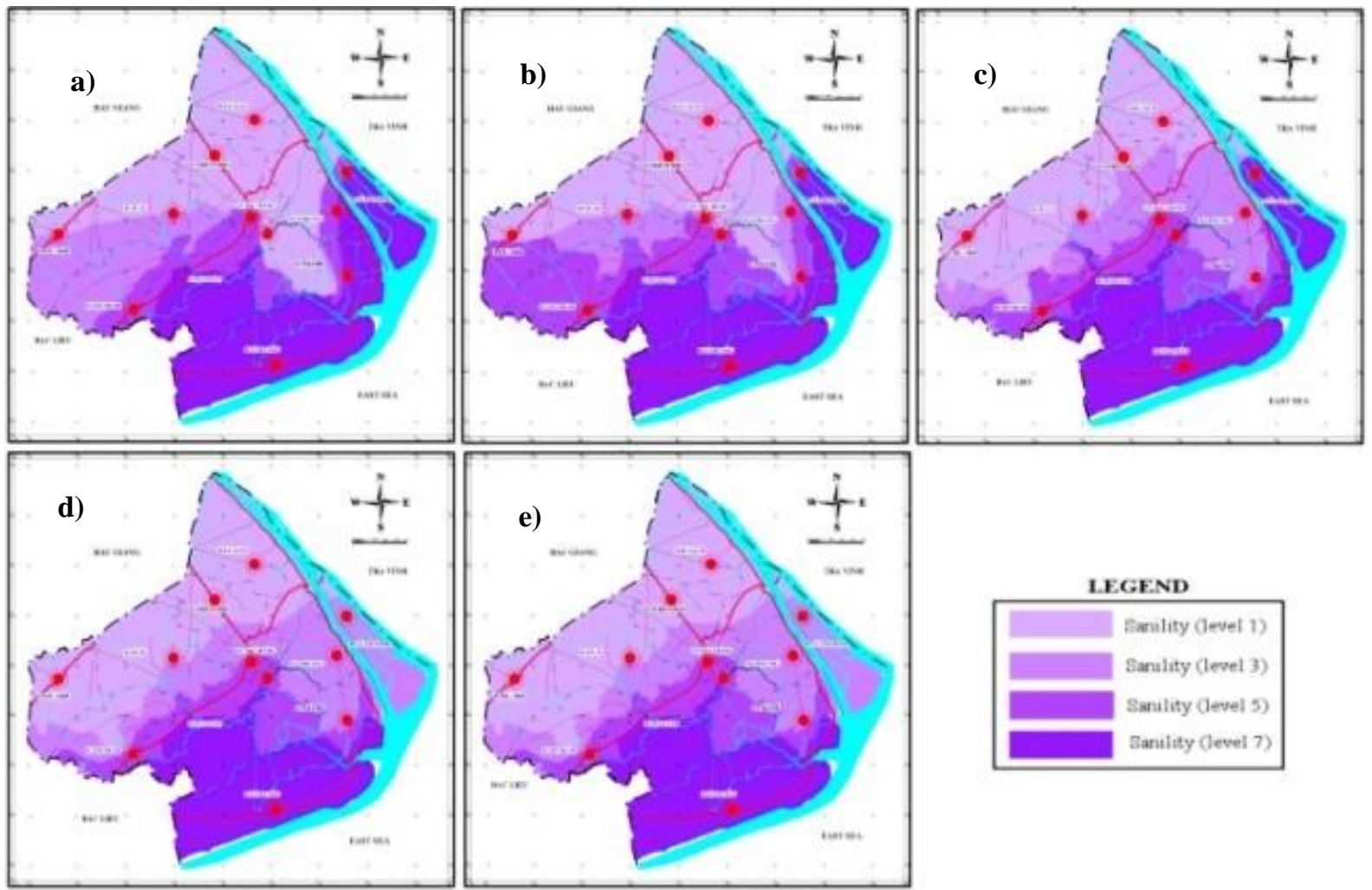

Fig. 4 Salt map in Soc Trang province. a) February, b) March, c) April, d) May and e) June. 


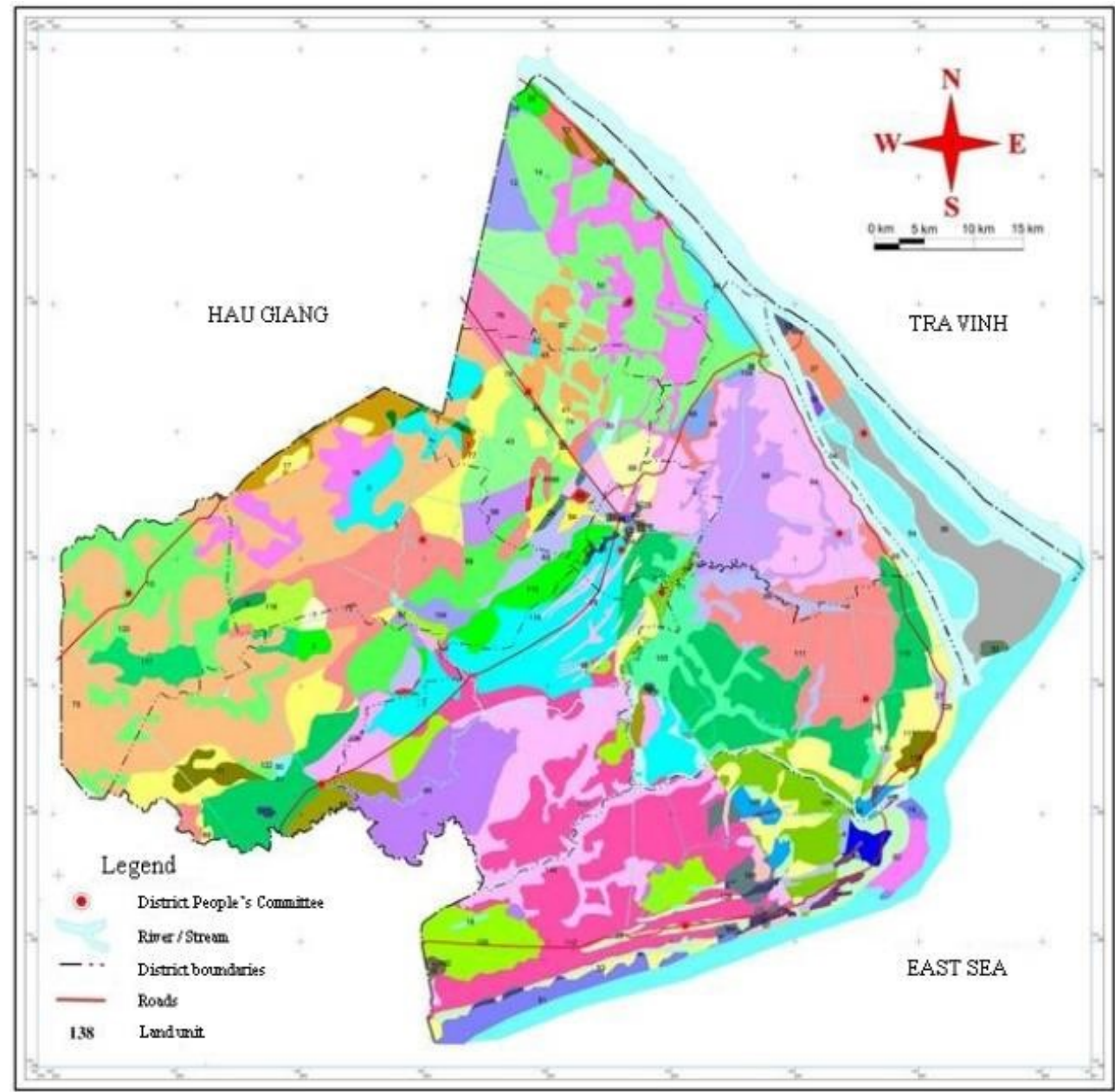

Fig. 5 Map of land unit in Soc Trang province.

Table 3 Threshold selection of salinity, rainfall and elevation.

\begin{tabular}{llll}
\hline & Salinity & Rainfall & Elevation \\
\hline Low & $0 \leq 2 \% 0$ & $<500 \mathrm{~mm}$ & $<0.63 \mathrm{~m}$ \\
Average & $2 \leq 3 \% 0$ & $500-1,000 \mathrm{~mm}$ & $0.63-1.09 \mathrm{~m}$ \\
High & $3 \leq 5 \% 0$ & $>1,000 \mathrm{~mm}$ & $>1.09 \mathrm{~m}$ \\
Very high & $\geq 5 \%$ & & \\
\hline
\end{tabular}

Table 4 Decentralized adaptability for salinity-proof rice breeds.

\begin{tabular}{lllll}
\hline Diagnostic elements & \multicolumn{4}{c}{ Decentralized adaptability } \\
\cline { 2 - 5 } & S1 & S2 & S3 & $\mathrm{N}$ \\
\hline Salinity penetration & Low & - & Average $(2-<3)$ & $\begin{array}{l}\text { Much } \\
\text { salinity }(3-<5)\end{array}$ \\
I\%o) & salinity $(0-<2)$ & $>3$ months & $<3$ months $(\geq 1.09)$ & - \\
(elevation-m) & Gravity flow $(0<0.63)$ & $(0.63<1.09)$ & Fluvisol & Arenosol \\
Land types & Gleysol & Luvisol & $<600$ & 0 \\
Average rainfall & $>1,000$ & $500-1,000$ & & 0 \\
\hline
\end{tabular}

and the comparison between land characteristics and the land requirements of rice breeds that decentralization adaptation of advance salinity-proof rice breeds have been adapted decentralization table of rice breeds. Decentralization factor is the division values of each land use requirement, diagnose 
conditions of soil quality in soil mapping unit. The adaptive decentralization based on the structure of land classification according to FAO [3].

With salinity-proof rice breeds that is less salty $1 \%$ $\leq 2 \%$ (low salt), the rice was affected at the first level, sprout and grew almost normally but the tip of the leaf and half on the leaves were white and rolled so the adaptive level is $\mathrm{S} 1$ and adaptation in salinity from $2 \leq$ $3 \%$ (salinity level 3 ). The phenomenon of early rice flag leaves few traces or white, slightly rolled leaves so poorly adapted varieties S3 and not adapted to salinity concentrations greater than $3 \%$. This process evaluated salinity-proof rice breeds which are less adaptive so adaptation capability is not high, however this adaptation will be upgraded in the higher salinity-proof rice breeds to higher adaptive capability and when the quality of land and water are improved.

\subsection{Test Results of Promising Salinity-proof Rice Breeds}

After the salinity-proof rice breeds were selected through different experiments, they came out in the trial production in different places of province to assess again the adaptable capability before mass production. For the "rice varieties in production test", all were farmers, seminar participants were selected at the same assessment. The Center of Seed and Plant Soc Trang province selected six sets of salinity-proof rice breeds giving the same results in the test production: the difficulty is 23 seed varieties and OM576 control, the A1 is 14 seed varieties and OM2717 controls, the salt-tolerance of 26 breeds and varieties OM576 1 control, the new salt-tolerant varieties is 9 seed varieties and OM576 same control, the same A0 is 12 seed varieties and OM2517 control and the performance is 20 varieties grown in Vinh Chau, My Xuyen and $\mathrm{Cu}$ Lao Dung, is the district with higher salt concentrations in other districts and low adaptive capacity.

During the experiment, Center of Seed and Plant Soc Trang province was constantly monitoring the agronomic traits such as yield components: growth period, plant height, length cotton, cotton per square meter, 1,000 grain weight, grains per cotton and yield of six of the same reality.

The salinity concentration of water was not very high during the experiment, however the experiment was in salinity land for a long time so most rice breeds had a slow growth after transplanting. The salinity concentration of water was $0.4 \%$ in My Xuyen station thus most rice breeds were impacted and less recovery was obtained in the first period. After an extended, the rate of dead rice breeds was high and it affected in the next evaluation step because for some varieties the survival rate was very low. The $\mathrm{Cu}$ Lao Dung station had low salinity, so the rice recovered early and then developed normal. Results of the experiment showed that there is a similar number of required to meet good salt tolerance, high yield and less disease.

The different experiments used different yield. Yield of rice breeds in $\mathrm{Cu}$ Lao Dung was higher than the yield of rice varieties in Vinh Chau and My Xuyen, which proved productivity is related to both salinity levels and land. These salinity-proof rice breeds have been experimented in all districts of the province. The breeds from the production test were selected in the field for higher yield assay. They proved that salinity-proof rice breeds can be applied widely to grow in the field. Salinity concentrations decrease concentrations in the assaying field are not severely affected by soil salinity, the yield is equally productive.

Table 5 Yield of rice breeds selected from the results of experiment and entrance tests and salinity-proof rice breeds [6].

\begin{tabular}{llll}
\hline \multirow{2}{*}{ Seed name } & \multicolumn{3}{l}{ Yield } \\
\cline { 2 - 4 } & My Xuyen & Cu Lao Dung & Vinh Chau \\
\hline OM 6932 & 4.90 & 4.60 & 3.7 \\
OM 6904 & 3.84 & 3.88 & 3.6 \\
OM 6976 & 3.41 & 4.40 & 4.1 \\
OM 576 & 3.62 & 4.40 & 3.2 \\
OM 6916 & 3.76 & 4.50 & 3.9 \\
OM 7347 & 4.03 & 5.17 & 3.6 \\
OM 7364 & 4.15 & 5.45 & 3.4 \\
\hline
\end{tabular}




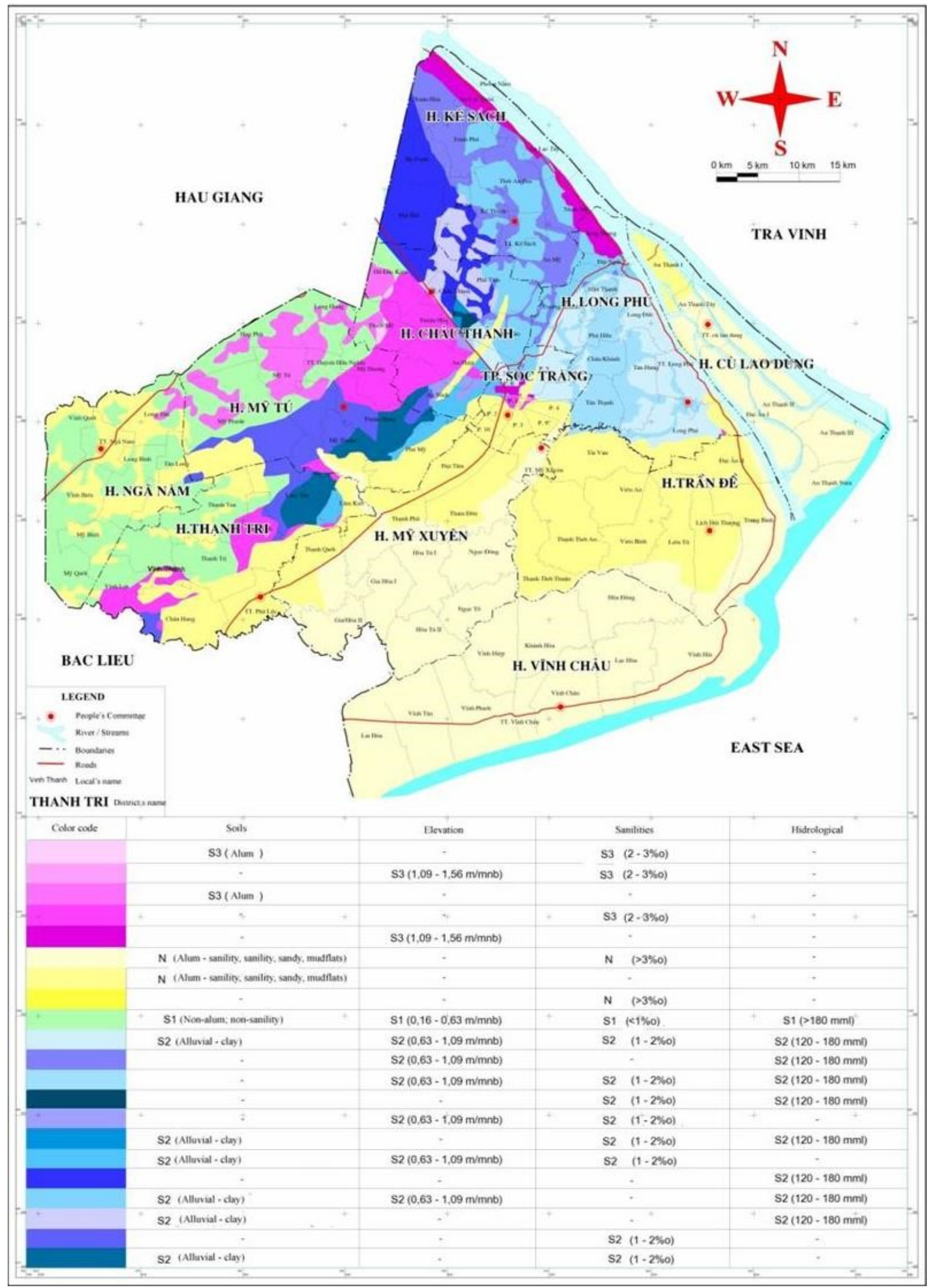

Fig. 6 Map of adaptability zoning for salinity-proof rice breeds in Soc Trang. 
Table 6 Comparison between yields of rice varieties selected from the experiment results, salinity-proof rice breeds and yields in the production of test.

\begin{tabular}{lllllllllll}
\hline \multirow{2}{*}{ Seeds } & \multicolumn{3}{c}{ Yield of test } & \multicolumn{3}{c}{ Yield in My Tu } & \multicolumn{3}{c}{ Yield in Thanh Tri } & \multicolumn{2}{c}{ Yield in Tran De } \\
\cline { 2 - 11 } & \multirow{2}{*}{ My Xuyen } & W-S & S-A & W-S & W-S & S-A & W-S & W-S & S-A & W-S \\
& & $10-11$ & 2011 & $11-12$ & $10-11$ & 2011 & $11-12$ & $10-11$ & 2011 & $11-12$ \\
\hline OM 576 & 3.62 & $5.26 \mathrm{~b}$ & $6.15 \mathrm{a}$ & $5.95 \mathrm{c}$ & $6.93 \mathrm{~cd}$ & $5.87 \mathrm{~b}$ & $5.53 \mathrm{~d}$ & $5.43 \mathrm{~d}$ & $4.93 \mathrm{~b}$ & $6.20 \mathrm{~b}$ \\
OM 6904 & 3.84 & & $5.98 \mathrm{ab}$ & $6.7 \mathrm{a}$ & & $6.77 \mathrm{a}$ & $7.50 \mathrm{a}$ & & $6.17 \mathrm{a}$ & $6.73 \mathrm{ab}$ \\
OM 6932 & 4.90 & & $5.78 \mathrm{bc}$ & $6.55 \mathrm{ab}$ & & $6.13 \mathrm{a}$ & $7.80 \mathrm{a}$ & & $5.93 \mathrm{a}$ & $6.93 \mathrm{ab}$ \\
OM 7347 & 4.03 & $5.56 \mathrm{~b}$ & $5.58 \mathrm{c}$ & $6.1 \mathrm{~b}$ & $7.03 \mathrm{c}$ & $6.60 \mathrm{a}$ & $7.08 \mathrm{ab}$ & $5.93 \mathrm{c}$ & $5.27 \mathrm{~b}$ & $7.23 \mathrm{a}$ \\
OM 7364 & 3.15 & $5.54 \mathrm{~b}$ & $5.35 \mathrm{~cd}$ & $6.58 \mathrm{ab}$ & $6.73 \mathrm{~d}$ & $6.40 \mathrm{a}$ & $6.53 \mathrm{c}$ & $6.33 \mathrm{ab}$ & $6.30 \mathrm{a}$ & $6.27 \mathrm{~b}$ \\
OM 6976 & 3.41 & $6.58 \mathrm{a}$ & & & $8.35 \mathrm{a}$ & & & $5.98 \mathrm{bc}$ & \\
OM 6916 & 3.76 & $5.5 \mathrm{~b}$ & & & $7.53 \mathrm{~b}$ & & & $6.60 \mathrm{a}$ & \\
\hline
\end{tabular}

\section{Conclusion}

The season usually highly affected by the elements of the Earth, irrigation capability and the ability to salinity penetration therefore the area of adaptive $\mathrm{S} 1$ is not very high and concentrated in Nga Nam district, My Tu. Adaptation S2 was the highest in Long Phu, KeSach, Chau Thanh district and Soc Trang city. Besides, they were limited by swelling clay, slightly higher elevation ( 0.63 to $1.09 \mathrm{~m} / \mathrm{mnb})$, less than $2 \%$ salinity and not high rainfall. Adaptation S3 was limited by alkaline land, water salinity greater than $2 \%$ largely in Chau Thanh and My Tu district. Others were not adapted, the majority in My Xuyen, Vinh Chau, Tran De and $\mathrm{Cu}$ Lao Dung district. On the other hand, the fact that the districts have served actively salted water for aquaculture and salt, in addition to restrictions from the soil element, this area less suitable for rice cultivation.

The results of adapted decantation were quite accurate and proven by the results of salinity-proof rice breeds tests in areas poorly adapted (ex: My Xuyen, $\mathrm{Cu}$ Lao Dung and Vinh Chau district). In addition, the salinity-proof rice breeds have low yield which still exists and develops in the regions. But they have higher yield when cultivated in other districts in the province. In summary, GIS and remote sensing techniques are effective tools in adaptive decentralization for salinity-proof rice breeds in Soc Trang province.

\section{Acknowledgements}

The authors wish to thank contributing authors for their time and expertise to support this paper through the site of study and guidance. The authors would also like to express their gratitude to the following experts for providing their valuable time to carrying out the external peer review of the paper, and to those who provided further information, images and guidance: Center of Seed and Plant in Soc Trang Province, Department of Irrigation Soc Trang province, and Soc Trang government. The field data and rice statistics were collected with the help of the staff from the Center of Seed and Plant Soc Trang Province.

\section{References}

[1] Center of Seed and Plant in Soc Trang Province. 2012. The Survey Data, Statistics and Reports to Seed Yield Varieties of Winter and Spring 2011-2012 and Summer-Autumn 2012.

[2] Department of Irrigation Soc Trang Province. 2011. Report Salinization Soc Trang.

[3] FAO. 1976. "A Framework for Land Evaluation.” FAO Soil Bulletin 32, FAO, Rome.

[4] FAO. 1993. "Guidelines for Land-Use Planning." FAO Development Series (1): 96.

[5] Huynh Ngoc Van. 2005. "Building Management System Database and Methodology to Evaluate the Applicability of High-Yielding Rice Varieties in Soc Trang Province in Geographic Information Systems.” Graduate thesis. Faculty of Agriculture and Applied Biology, Can Tho University.

[6] Nguyen Thi Bap. 2011. "Test Results and Selection of Salt-Tolerant Rice Varieties in 2010.” Scientific Research Projects. Center of Seed and Plant Soc Trang Province. 